\title{
CONF- $960848-28$
}

ERNEST DRLANDQ LAWRENLE

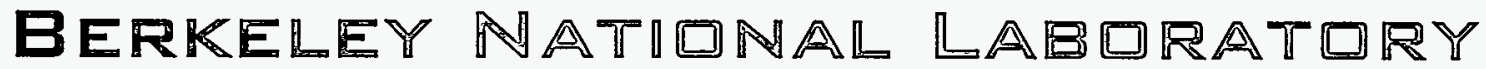

\section{Performance of the VUV High Resolution and High Flux Beamline for Chemical Dynamics Studies at the Advanced Light Source}

P.A. Heimann, M. Koike, C.W. Hsu, M. Evans, C.Y. Ng, D. Blank, X.M. Yang, C. Flaim, A.G. Suits, and Y.T. Lee Accelerator and Fusion Research Division

\section{RECEIVED SEP 201996 OSTI}

July 1996

Presented at

SPIE,

Denver, $\mathrm{CO}$, August 5-9, 1996, and to be published in the Proceedings 


\section{DISCLAIMER}

This document was prepared as an account of work sponsored by the United States Government. While this document is believed to contain correct information, neither the United States Government nor any agency thereof, nor The Regents of the University of California, nor any of their employees, makes any warranty, express or implied, or assumes any legal responsibility for the accuracy, completeness, or usefulness of any information, apparatus, product, or process disclosed, or represents that its use would not infringe privately owned rights Reference herein to any specific commercial product, process, or service by its trade name, trademark, manufacturer, or otherwise, does not necessarily constitute or imply its endorsement, recommendation, or favoring by the United States Government or any agency thereof, or The Regents of the University of California. The views and opinions of authors expressed herein do not necessarily state or reflect those of the United States Government or any agency thereof, or The Regents of the University of Califomia. 


\section{DISCLAIMER}

Portions of this document may be illegible in electronic image products. Images are produced from the best available original document. 


\section{DISCLATMER}

This report was prepared as an account of work sponsored by an agency of the United States Government. Neither the United States Government nor any agency thereof, nor any of their employees, makes any warranty, express or implied, or assumes any legal liability or responsibility for the accuracy, completeness, or usefulness of any information, apparatus, product, or process disclosed, or represents that its use would not infringe privately owned rights. Reference herein to any specific commercial product, process, or service by trade name, trademark, manufacturer, or otherwise does not necessarily constitute or imply its endorsement, recommendation, or favoring by the United States Government or any agency thereof. The views and opinions of authors expressed herein do not necessarily state or reflect those of the United States Government or any agency thereof. 
LBL-39138

LSBL-344

UC-410

\title{
Performance of the VUV High Resolution and High Flux Beamline for Chemical Dynamics Studies at the Advanced Light Source
}

\author{
P.A. Heimann, ${ }^{1}$ M. Koike, ${ }^{2}$ C.W. Hsu, ${ }^{3}$ M. Evans, ${ }^{4}$ C.Y. Ng, ${ }^{4}$ D. Blank, ${ }^{3}$ \\ X.M. Yang, ${ }^{3}$ C. Flaim, ${ }^{1}$ A.G. Suits, ${ }^{3}$ and Y.T. Lee ${ }^{3 *}$ \\ ${ }^{1}$ Advanced Light Source \\ Accelerator and Fusion Research Division \\ Ernest Orlando Lawrence Berkeley National Laboratory \\ University of California \\ Berkeley, California 94720 \\ ${ }^{2}$ Center for X-Ray Optics \\ Materials Sciences Division and \\ ${ }^{3}$ Chemical Sciences Division \\ Ernest Orlando Lawrence Berkeley National Laboratory \\ University of California \\ Berkeley, California 94720 \\ ${ }^{4}$ Department of Chemistry \\ Iowa State University \\ Ames, Iowa 60011
}

*Permanent address: Institute of Atomic and Molecular Sciences, Academia Sinica, Taipei 10764, Taiwan

July 1996

This work was supported by the Director, Office of Energy Research, Office of Basic Energy Sciences, Materials Sciences Division, of the U.S. Department of Energy under Contract No. DE-AC03-76SF00098. 
Recycied Paper

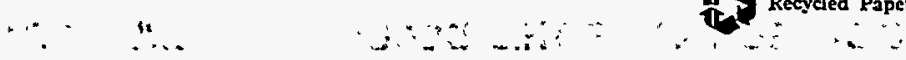




\title{
Fon SPIE Proceedings
}

Performance of the VUV high resolution and high flux beamline for chemical dynamics sturutes at the Advanced Light Source

\author{
P.A. Heimann, ${ }^{1}$ M. Koike, ${ }^{2}$ C.W. Hsu, ${ }^{3}$ M. Evans, ${ }^{4}$ C.Y. Ng, ${ }^{4}$ D. Blank, ${ }^{3}$ X.M. Yang, ${ }^{3,}{ }^{*}$ \\ C. Flaim, ${ }^{1}$ A.G. Suits ${ }^{3}$ and Y.T. Lee ${ }^{3, *}$ \\ ${ }^{1}$ Advanced Light Source, Accelerator and Fusion Research Division, \\ ${ }^{2}$ Center for X-ray Optics, Materials Sciences Division, and ${ }^{3}$ Chemical Sciences Division, \\ Lawrence Berkeley National Laboratory, Berkeley, CA 94720, USA and \\ ${ }^{4}$ Department of Chemistry, Iowa State University, Ames, IA 50011, USA \\ *Permanent address: Institute of Atomic and Molecular Sciences, Academica Sinica, Taipei 10764, Taiwan
}

\begin{abstract}
At the Advanced Light Source an undulator beamline, with an energy range from 6 to $30 \mathrm{eV}$, has been constructed for chemical dynamics experiments. The higher harmonics of the undulator are suppressed by a novel, windowless gas filter. In one branchline high flux, $2 \%$ bandwidth radiation is directed toward an end station for photodissociation and crossed molecular beam experiments. A photon flux of $10^{16}$ photon/sec has been measured at this end station. In a second branchline a $6.65 \mathrm{~m}$ offplane Eagle monochromator delivers narrow bandwidth radiation to an end station for photoionization studies. At this second end station a peak flux of $3 \times 10^{11}$ was observed for 25,000 resolving power. This monochromator has achieved a resolving power of 70,000 using a 4800 grooves $/ \mathrm{mm}$ grating, one of the highest resolving powers obtained by a VUV monochromator.
\end{abstract}

Keywords: synchrotron beamline, VUV monochromator

\section{INTRODUCTION}

At the Advanced Light Source a beamline has been designed for chemical dynamics experiments. Two different classes of investigations are being performed both relating to gas phase reaction dynamics with an emphasis on understanding combustion chemistry. In the combustion of hydrocarbons many reaction steps occur involving transient species. The reaction pathways and energetics of these transient species are not well understood. Three end stations have been constructed accommodating various measurement techniques and illumination conditions depending on the purposes of the experiments.

In the first end station photochemistry and chemical reactivity are being studied. Molecular and free radical photodissociation are initiated by a laser, or two molecular beams cross under single collision conditions. After an appropriate flight distance the resultant molecular species are ionized by the synchrotron beam. As an ionization source synchrotron radiation can selectively differentiate products based on ionization potential while minimizing fragmentation. Recently, another end station has been added to the white beam branch for performing reactive scattering utilizing imaging detection.

In the second end station chemical energetics are studied by photoelectron spectroscopy and photoionization. The synchrotron radiation photoionizes a molecular beam with near zero kinetic energy electrons detected by a steradiency analyzer and ions collected by either a time-of-flight or quadrupole mass spectrometer. Coincidence techniques may be used to separate the photoionization yield of each component of a mixed molecular beam.

The two sets of experiments pose different performance requirements of the optical design. For photodissociation and reactive scattering the need is for as high a flux as possible to detect very low number densities, while resolution may be compromised. The undulator fundamental can selectively ionize molecules and molecular fragments based on their ionization potential. For molecular spectroscopy and photoionization the highest resolving power is desired, with a target set at 100,000. At the same time for a given resolution, the intensity must be maximized as well." In common, these experiments request excellent harmonic purity to allow threshold studies. From the dimensions of the molecular beams, a focus in the end stations of $1 \mathrm{~mm}^{2}$ is adequate. 
The beamline as it was constructed is described in section 2. In section 3 the characterization of the gas filter will be presented. The measurement of the flux from both the white beam and monochromator branchlines will be described in section 4. Finally, section 5 presents the determination of the off-plane Eagle monochromator resolution.

\section{DESCRIPTION OF THE BEAMLINE}

The ALS Chemical Dynamics beamline consists of an undulator, a common section, followed by two branches and three end stations. Fig. 1 shows a schematic layout drawing of the beamline. The parameters for the optical elements are listed in Table I. The design of the beamline has been described in Koike et al. ${ }^{1}$

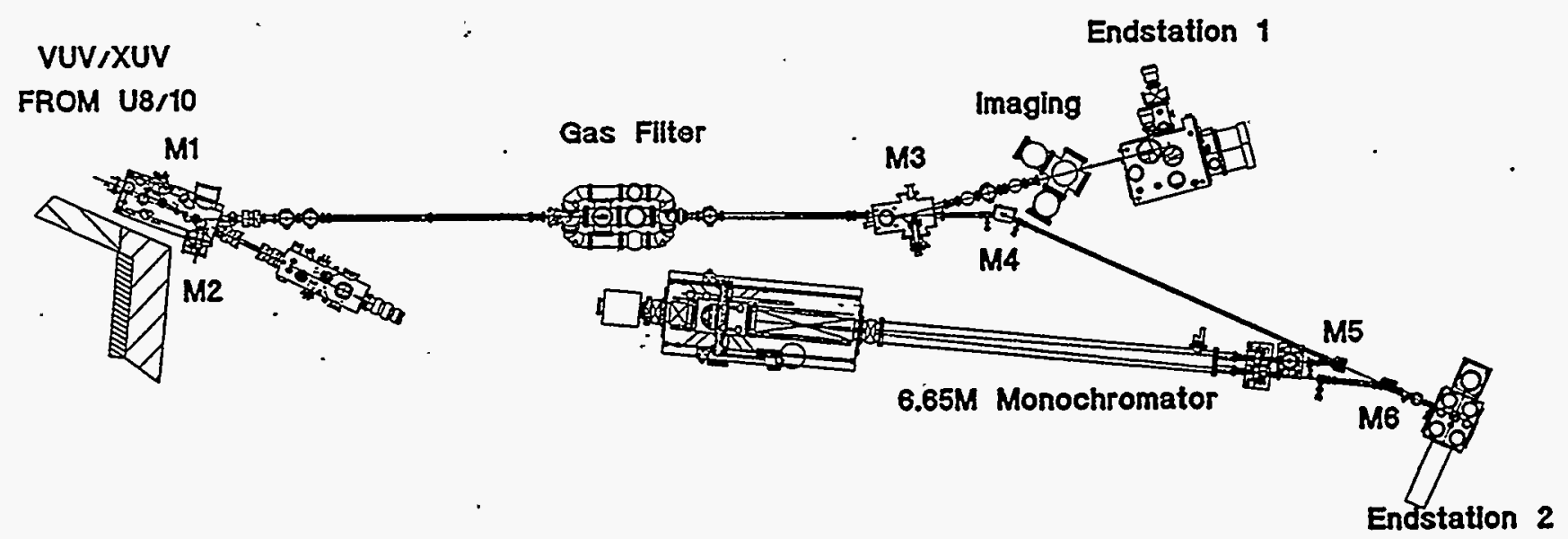

Figure 1. Schematic diagram of the beamline: M1, spherical mirror, M2, retractable toroidal mirror; gas filter, M3, retractable toroidal mirror, M4 and M5, cylindrical mirrors, $6.65-\mathrm{m}$ off-plane Eagle type monochromator, M6, toroidal mirror; imaging end station, end station 1 and end station 2 . The view in the horizontal plane is shown.

Initially, an $8 \mathrm{~cm}$ period undulator (U8) was installed, which provided a minimum photon energy of $18.5 \mathrm{eV}$ at $1.5 \mathrm{GeV}$ electron beam energy. In September, 1995 that undulator was exchanged with a $10 \mathrm{~cm}$ period undulator (U10) delivering radiation over the whole photon energy range of the beamline, from 5 to $30 \mathrm{eV}$. The U10 undulator has 43 periods. Operating at high $\mathrm{K}$ the undulator source emits a spectrum with many harmonics and a high total power.

In the common section of the beamline, the undulator spectrum is modified by two mirrors and a harmonic filter. The M1, M2 mirror chamber is a branching point between the Chemical Dynamics beamline and a second beamline for atomic and molecular physics. The switching of the beam between the two beamlines is actuated by the insertion or retraction of the M2 mirror. The power is to a large extent removed by the $M 1$ and $M 2$ mirrors, whose substrates are made of GlidCop metal with internal water cooling channels. The silicon-coated $\mathrm{M} 2$ miror has a reflectivity cutoff near $70 \mathrm{eV}$ photon energy. The spherical M1 mirror and toroidal M2 mirror produce a convergent beam focused at the center of the gas harmonic filter. The gas filter suppresses all the remaining harmonics except the fundamental. ${ }^{2}$ Horizontal and vertical apertures define the acceptance from the undulator source and provide some bandwidth selectivity. In the white beam branchline the toroidal mirror M3 images the beam from the gas filter into end station 1 . Insertion or retraction of the M3 mirror switches the beam between the white beam and monochromatic branchlines.

The flux at end station 1 was calculated to be about $10^{16}$ photon/sec with a slow variation with energy. ${ }^{1}$ A silicon coating was chosen for the M2 and M3 mirrors because of the high grazing incidence reflectivity of silicon, for example higher than the VUV reflectivity of platinum. Silicon coatings have been observed to have oxygen and carbon impurities. ${ }^{3}$ The minimum bandwidth of the fundamental is $2.3 \%$ derived from the 43 undulator periods. The bandwidth and intensity may be increased by opening the horizontal and vertical apertures with a limit set by the differential pumping of the gas filter. From ray tracing spot diagrams, the spot size in the end station 1 is predicted to be $50 \mu \mathrm{m}$ vertically by $170 \mu \mathrm{m}$ horizontally (fwhm). ${ }^{1}$ 
Table I. Optical elements of the beamline.

\begin{tabular}{|c|c|c|c|c|c|}
\hline & Type & $\begin{array}{l}\text { Coating and } \\
\text { blank material }\end{array}$ & $\begin{array}{l}\text { Radius } \\
\text { (m) }\end{array}$ & Incidence angle $\left(^{\circ}\right)$ & $\begin{array}{c}\text { Groove density } \\
(\mathrm{l} / \mathrm{mm}) \\
\text { and blaze } \lambda\end{array}$ \\
\hline M1 & $\begin{array}{l}\text { Spherical } \\
\text { mirror }\end{array}$ & $\begin{array}{l}\mathrm{Ni} \text { and } \mathrm{C} \text { coated } \\
\text { GlidCop }\end{array}$ & 302.3 & 87.0 & - \\
\hline M2 & $\begin{array}{l}\text { Toroidal } \\
\text { mirror }\end{array}$ & Si-coated GlidCop & $\begin{array}{l}66.3(\mathrm{~h}) \\
1.73(\mathrm{v}) \\
\end{array}$ & 77.0 & - \\
\hline M3 & $\begin{array}{l}\text { Toroidal } \\
\text { mirror }\end{array}$ & Si-coated GlidCop & $\begin{array}{l}29.2(\mathrm{~h}) \\
0.443(\mathrm{v}) \\
\end{array}$ & 83.0 & - \\
\hline M4X & $\begin{array}{l}\text { Toroidal } \\
\text { mirror }\end{array}$ & $\begin{array}{c}\text { Si-coated } \\
\text { Quartz }\end{array}$ & $\begin{array}{l}26.0(\mathrm{~h}) \\
1.15(\mathrm{v}) \\
\end{array}$ & 77.9 & - \\
\hline M4 & $\begin{array}{c}\text { Bendable } \\
\text { cylindrical } \\
\text { mirror } \\
\end{array}$ & Si-coated GlidCop & $28.5-24.9(\mathrm{~h})$ & 77.9 & - \\
\hline M5 & $\begin{array}{l}\text { Cylindrical } \\
\text { mirror }\end{array}$ & $\mathrm{SiC} \quad$ & $1.78(\mathrm{v})$ & 9.8 & - \\
\hline G1 & $\begin{array}{c}\text { Spherical } \\
\text { grating }\end{array}$ & $\begin{array}{c}\mathrm{Al} / \mathrm{MgF}_{2} \\
\text { coated Quartz (replica) }\end{array}$ & 6.65 & $\begin{array}{c}5.164 \\
(1500 \AA)\end{array}$ & $\begin{array}{r}1200 \\
1500 \AA\end{array}$ \\
\hline G2 & $\begin{array}{l}\text { Spherical } \\
\text { grating }\end{array}$ & $\begin{array}{c}\text { Os coated } \\
\text { Quartz (replica) }\end{array}$ & 6.65 & $\begin{array}{c}21.102 \\
(1500 \AA)\end{array}$ & $\begin{array}{l}4800, \\
1000 \AA \\
\end{array}$ \\
\hline M6 & $\begin{array}{l}\text { Toroidal } \\
\text { mirror }\end{array}$ & $\mathrm{Si}$ & $\begin{array}{l}15.8(\mathrm{~h}) \\
0.182(\mathrm{v})\end{array}$ & 81.0 & - \\
\hline
\end{tabular}

As the prefocus system for the monochromatic branchline, the cylindrical mirrors M4 and M5 produce a horizontally and vertically converging beam incident into the 6.65 - $\mathrm{m}$ off-plane Eagle type monochromator. To compensate the astigmatism of the monochromator, M4 is a bendable mirror to produce a variable horizontal focus point. The monochromator is equipped with two 6.65-m replica gratings having $1200 \mathrm{~V} / \mathrm{mm}$ from Milton Roy and $4800 \mathrm{l} / \mathrm{mm}$ from Hyperfine, Inc. A third, holographic grating with varied line spacing, which will require limited translation, is on order. ${ }^{4}$ The toroidal mirror M6 focuses rays from the exit slit into end station 2. Alternatively for photodissociation experiments, the M4X mirror focuses the white beam into end station 2 with the M5 and M6 mirrors removed.

An elevation view of the 6.65 -m off-plane Eagle monochromator, constructed by McPherson Corp., is shown in figure 2. The entrance slit is hidden behind the exit slit in figure 2; both are oriented horizontally. The slits have two adjustments, width $(5$ to $500 \mu \mathrm{m})$ and rotation angle, as well as occultors, which can mask the slit length. The gratings disperse the radiation vertically and may be rotated through a $30^{\circ}$ angle. The grating chamber is mounted on a granite table. The grating carriage and chamber independently ride on pairs of cross-roller bearing slides allowing a translation of $950 \mathrm{~mm}$. The range of rotation and translation motions permit the $4800 \mathrm{l} / \mathrm{mm}$ grating to scan from zero order to $2000 \AA$. The grating rotation and translation are driven by stepping motors with linear encoders and limit switches. In the case of rotation, the linear encoder is an alternative for a Hewlett Packard laser interferometer. This interferometer determines the rotation angle by measuring the path length between two beams reflected back from a pair of cube corners above and below the rotation axis. On top of the grating chamber are manipulators, which permit under vacuum the interchange of the 1200 and $4800 \mathrm{l} / \mathrm{mm}$ gratings and the adjustment of the pitch, roll and yaw angles of the gratings. On the right side is a deuterium lamp with an insertable-retractable mirror, which can provide UV radiation when the synchrotron beam is.not available. The deuterium lamp was used in testing the monochromator control software and in calibrating the entrance and exit slit widths. The monochromator is pumped by two $400 \mathrm{l} / \mathrm{s}$ ion pumps and a titanium sublimation pump (not shown in figure 2 ). 


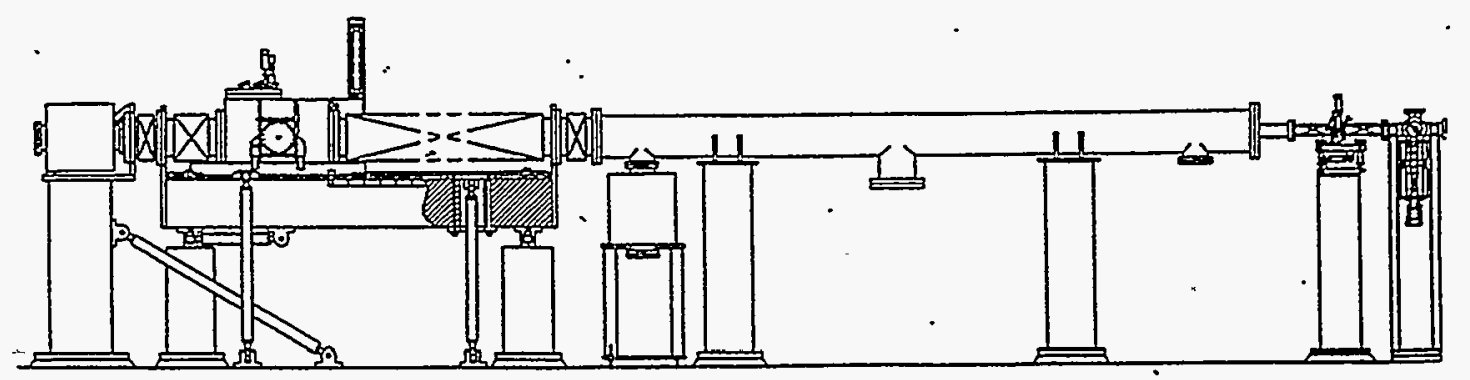

Figure 2. A layout drawing showing the elevation view of the $6.65 \mathrm{~m}$ off-plane Eagle monochromator constructed by McPherson. Shown from the right side are the deuterium lamp, the entrance and exit slits, vacuum chamber and translatable grating chamber.

The $\lambda$ of the off-plane Eagle monochromator is given by: 5

$$
m \lambda=2 d\left(1+\frac{z^{2}}{R^{2} \cos ^{2} \alpha}\right)^{-1 / 2} \sin \alpha,
$$

where $d$ is the grating period, $2 \mathrm{z}$ the separation between entrance and exit slits (174 mm), $R$ the grating radius and $\alpha$ the incidence (and diffraction) angle of the grating.

The 6.65-m off-plane Eagle monochromator was chosen to provide a high resolving power for spectroscopy experiments. Off-plane Eagle spectrographs have achieved very high resolution for absorption measurements. ${ }^{6,7}$ In addition, the off-plane Eagle mounting suppresses scattered light by deflecting the zero order away from the vertical plane through the exit slit. One added complexity is that as the grating translates the horizontal position of the beam on the exit slit will move unless there is a small, compensating rotation of the M5 mirror.

The flux, resolution and spot size provided at end station 2 were calculated. ${ }^{1}$ At end station 2 the calculated flux has a maximum in the mid-1012 photon/sec range for a resolving power of 25,000. The M4 and M6 mirrors have silicon optical surfaces. The M5 mirror was chosen as an uncoated CVD SiC mirror because of the high normal incidence reflectivity of CVD $\mathrm{SiC}$. Each grating has an efficiency maximum from the blaze angle: $8 \mathrm{eV}$ for the $1200 \mathrm{1} / \mathrm{mm}$ grating and $12 \mathrm{eV}$ for the 4800 $\mathrm{I} / \mathrm{mm}$ grating. A coating of $\mathrm{Al} / \mathrm{MgF}_{2}$ was selected for the $1200 \mathrm{~J} / \mathrm{mm}$ grating to provide high efficiency at low photon energies. The coating for the $4800 \mathrm{ymm}$ grating was chosen to be Os for good overall efficiency. The theoretical resolving power using the $4800 \mathrm{1} / \mathrm{mm}$ grating is estimated be $2 \times 10^{5}$. From spot diagrams the spot size is predicted to be $240 \mu \mathrm{m}$ vertically by $360 \mu \mathrm{m}$ horizontally (fwhm) in end station 2 .

\section{GAS HARMONIC FILTER}

Higher harmonics present in the undulator spectrum can dramatically increase the background level. For example in the experiments performed in end station 1, high energy photons may dissociatively ionize parent molecules or background gases. Because of these considerations a windowless harmonic filter has been developed employing rare gases (argon, neon or helium) as the filter medium and differential pumping to preserve the beamline vacuum. This gas harmonic filter has been described in detail in Ref. 2. Photons with energies exceeding the ionization potential of the rare gas are absorbed with very high efficiency. The harmonic filter consists of a gas cell and three differential pumping regions, both upstream and downstream of the cell. Each of these regions is separated by conductance limiting aperture tubes. In addition, on the branchline to end station $1, \mathrm{MgF}_{2}$ filter can be inserted in the beam to provide a lower photon energy cut-off. A further advantage is that the gas filter reduces the incident power to the level of tens of $\mathrm{mW}$, therefore eliminating the need for water cooled optics downstream. 
The performance of the gas filter was characterized with a Transmission Grating Spectrometer (TGS). ${ }^{8}$ During the measurements the TGS was installed at the end of the first branchline, behind end station 1 . The spectrum of the $8 \mathrm{~cm}$ period undulator was measured at $\mathrm{K}=5.24$, and the results shown in fig. 3 . In the absence of gas, a number of undulator harmonics are observed, with additional peaks present from higher diffraction orders of the transmission grating. The TGS sensitivity is, to first order, inversely proportional to $\lambda$. The intensities of the higher harmonics are strongly attenuated above $\sim 70 \mathrm{eV}(-180 \AA)$ by the $M 1, M 2$ and $M 3$ reflectivities. Integration of harmonic peaks in the spectrum with and without neon gas shows a suppression of greater than four orders of magnitude. In figure 2 the fundamental appears to have lower intensity when the neon gas was present in the gas filter compared with when the gas was absent. However, after correcting for the contributions of higher orders, the fundamental intensity is the same in both cases within the measurement uncertainty.

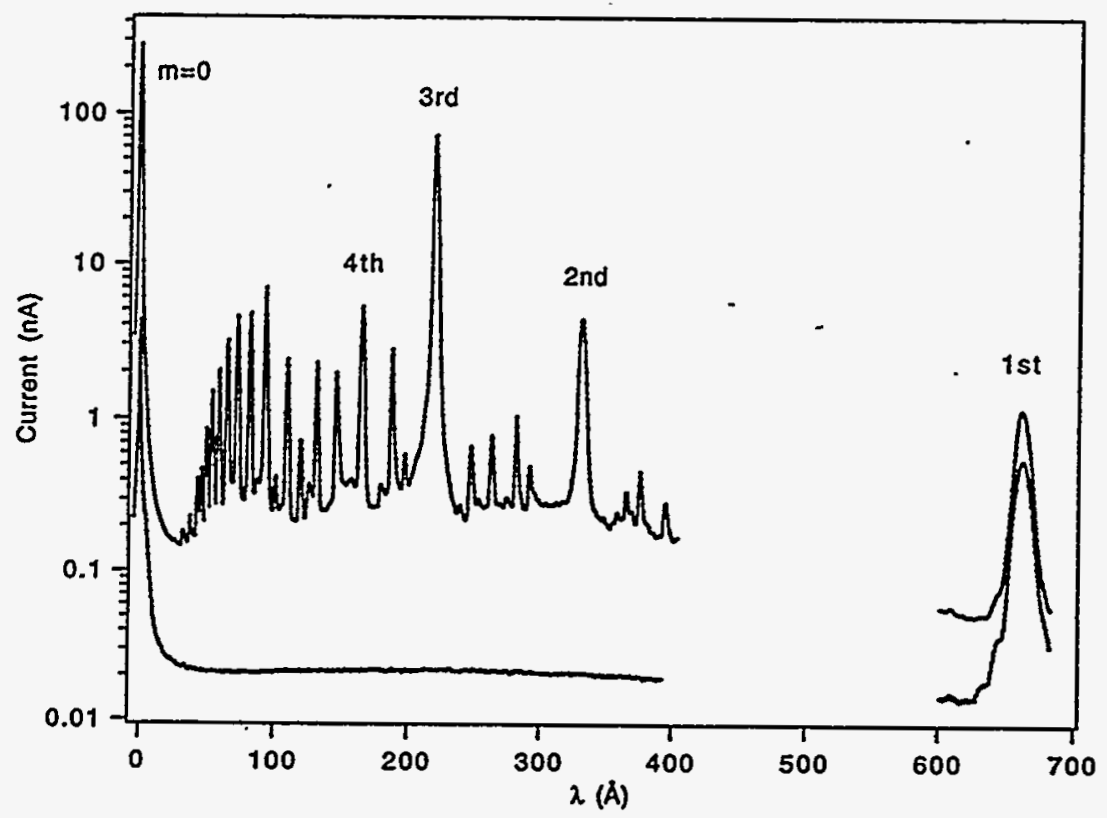

Figure 3. Undulator spectrum at $\mathrm{K}=5.24$ recorded without $\mathrm{Ne}$ (upper curves) and with 30.6 Torr $\mathrm{Ne}$ (lower curves) in the gas cell. First order contributions of the undulator harmonics are indicated. Contributions are also seen from higher orders of the grating.

The photon energy scale of the monochromator was calibrated using the gas filter as an absorption cell. The results for the $4800 \mathrm{l} / \mathrm{mm}$ grating are displayed in figure 4 . The photon energy was scanned through known absorption lines of argon, neon or helium with the appropriate gas being present in the gas filter. The resonances were observed as minima in the photon intensity, which was monitored in end station 2. In general, the absorption lines were measured in saturation. However, it is also possible to avoid saturation by switching from one gas to another and then scanning across a resonance of the first gas, which is then present in the gas filter as an impurity. It is estimated that the energy calibration is accurate to $1 \mathrm{meV}$.

\section{FLUX}

The flux on the white beam branch was measured with a UHV compatible calorimeter (Scientech, Inc.). Semiconductor photodiodes cannot be exposed to intensities of $10^{16}$ photon $/ \mathrm{sec} \mathrm{mm}^{2}$ because of beam damage. 9 On the other hand, a calorimeter, having a power range of $10 \mathrm{~mW}$ to $10 \mathrm{~W}$ and a nominal accuracy of $3 \%$, is well suited to observing the unmonochromatized undulator fundamental. One uncertainty in the calorimeter calibration in the VUV $\lambda$ region is derived from the reflectivity of the aluminum absorber. There is some evidence from the reflectivity of polished aluminum samples that the normal incidence reflectivity is low, less than 0.1 , for photon energies above $8 \mathrm{eV} .10$ No correction was made here for the absorber reflectivity. 


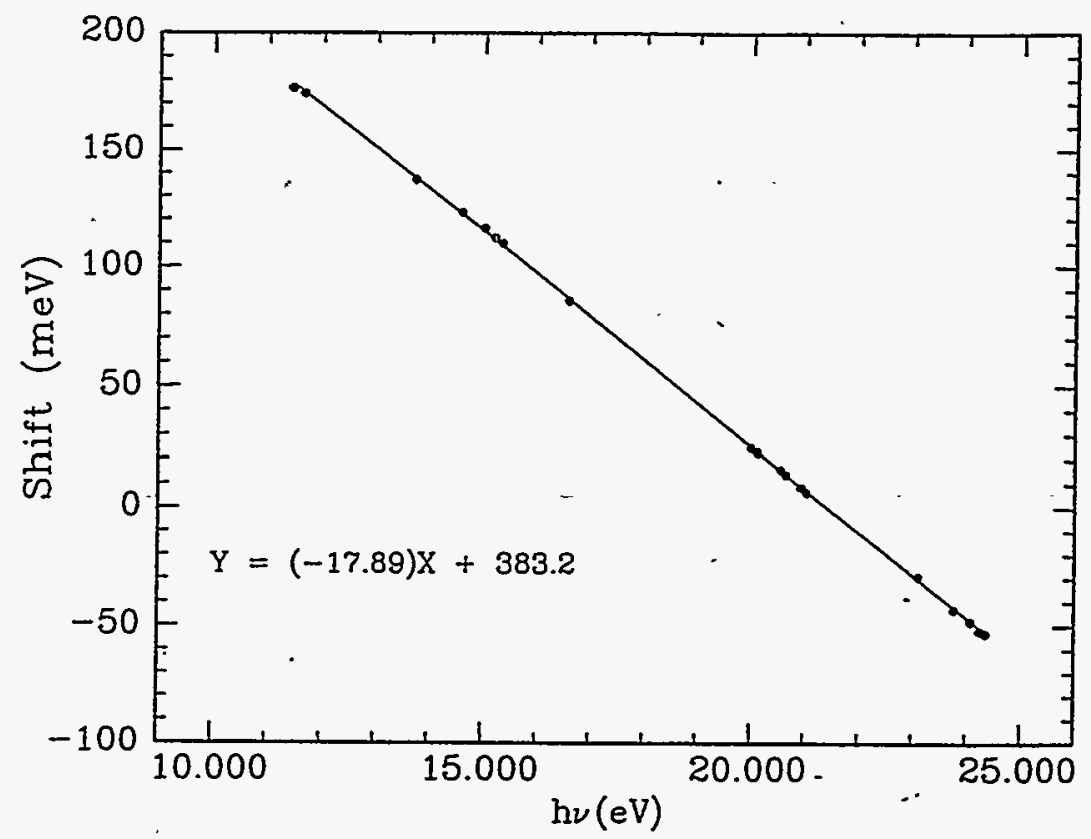

Figure 4. The photon energy calibration of the monochromator using the $4800 \mathrm{l} / \mathrm{mm}$ grating. Data are resonances of $\mathrm{Ar}$, Ne and He observed in the gas filter transmission.

The calorimeter was inserted after a differential pumping section following the M3 mirror chamber. The measured flux for different undulator gaps is shown in figure 5. The individual curves represent data sets taken with argon, neon or helium in the gas harmonic filter cell. The last curve, with open squares, shows the situation of a $\mathrm{MgF}_{2}$ filter placed in the beam in addition to argon in the gas harmonic filter. The calorimeter was calibrated in vacuum using the heater coil. The measured intensities were normalized to $400 \mathrm{~mA}$ beam current and a linear correction was made for the difference between the constant horizontal and vertical apertures used and those appropriate for $2.5 \%$ bandwidth.

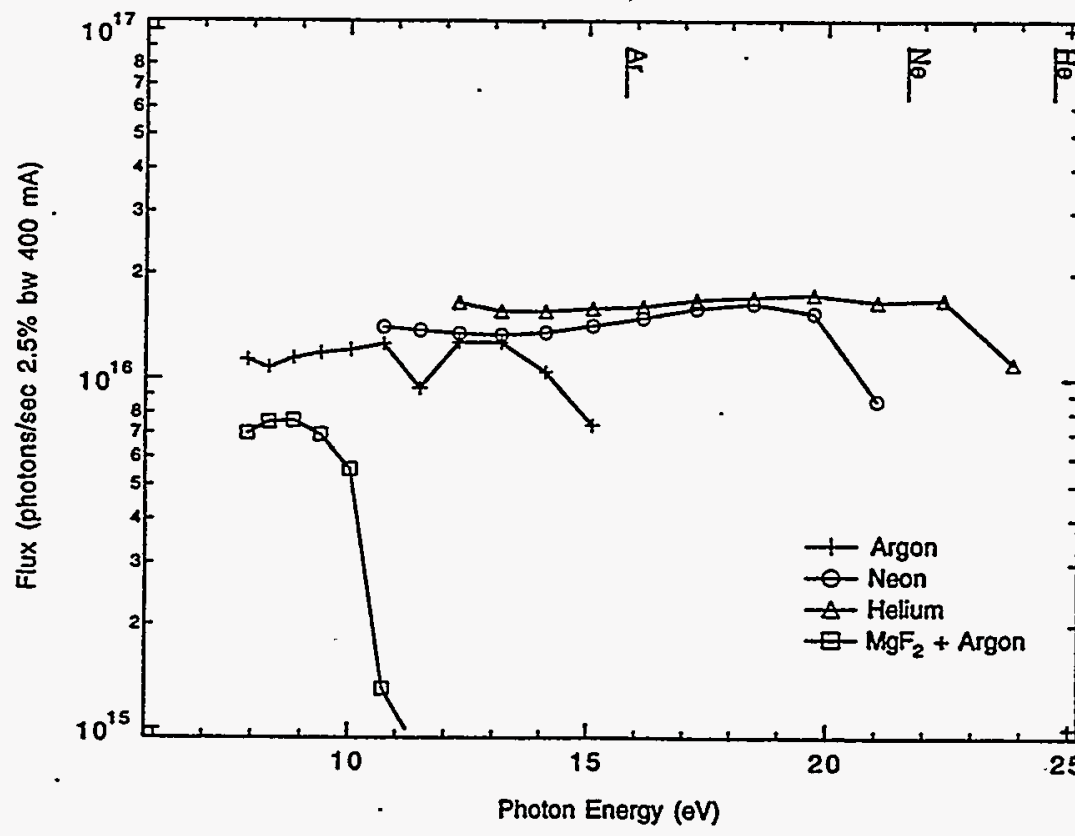

Figure 5. The flux through the branch line to end station 1 measured with a calorimeter. Different rare gases, $\mathrm{Ar}, \mathrm{Ne}$ and $\mathrm{He}$, were present in the gas filter, and in one case a $\mathrm{MgF}_{2}$ filter was inserted in the beam. Vertical lines mark the ionization potentials of $\mathrm{Ar}, \mathrm{Ne}$ and $\mathrm{He}$. 
The intensity curves fall off near the ionization potentials of the gas in the harmonic filter because of the Rydberg series converging on the ionization potentials. At $11.5 \mathrm{eV}$ photon energy a dip is observed from the saturated argon $4 \mathrm{~s}$ and $4 \mathrm{~s}^{\prime}$ resonances. ${ }^{11}$ The measured flux is smaller than the calculated flux by a factor of two or less depending on the photon energy. This difference should be attributed to the non-ideal composition of the Si optical coatings on the M2 and M3 mirrors. The difference in intensity at a given photon energy with different gases in the harmonic filter indicates a background component of the radiation in addition to the fundamental peak. The integrated intensity of the background can be roughly estimated from the measurements at $13.2 \mathrm{eV}$ photon energy, giving about $10 \%$. A source of the background radiation is considered to be the ends of the undulator, where the peak magnetic field is decreased. The background radiation at energies above the fundamental, although reiatively weak, compromises the selectivity of the undulator as an ionization detector. For photon energies of $10 \mathrm{eV}$ and below, a MgF 2 filter can be inserted in the beam to provide a lower energy cut-off of the background at a cost of a $35 \%$ decrease in intensity. Subsequent to the flux measurement shown in figure 3, the absorption in the $\mathrm{MgF}_{2}$ filter increased because of color center formation.

The photon flux of the monochromatic branch line was measured with a Si n-on-p photodiode (International Radiation Detectors) mounted temporarily inside end station 2. This detector was calibrated over the energy range from 4.9 to $23.9 \mathrm{eV}$ at the National Institute of Science and Technology. The calibration accuracy was $10 \%$ on average, depending on the photon energy. Although this $\mathrm{Si}$ photodiode was nitrided to increase its radiation hardness, it can be damaged with doses of radiation greater than $10^{16}$ photons $/ \mathrm{cm}^{2} .12$ Attempts were made to limit the exposure of the detector to radiation.

The measured flux through the Eagle monochromator with either 1200 or $4800 \mathrm{l} / \mathrm{mm}$ grating is shown in figure $\dot{6}$. The undulator gap was set to different discrete values, and the grating angle $(\alpha)$ was varied through the maximum. The entrance and exit slit widths were both set to $50 \mu \mathrm{m}$. The flux was normalized to $400 \mathrm{~mA}$ and 25,000 resolving power.

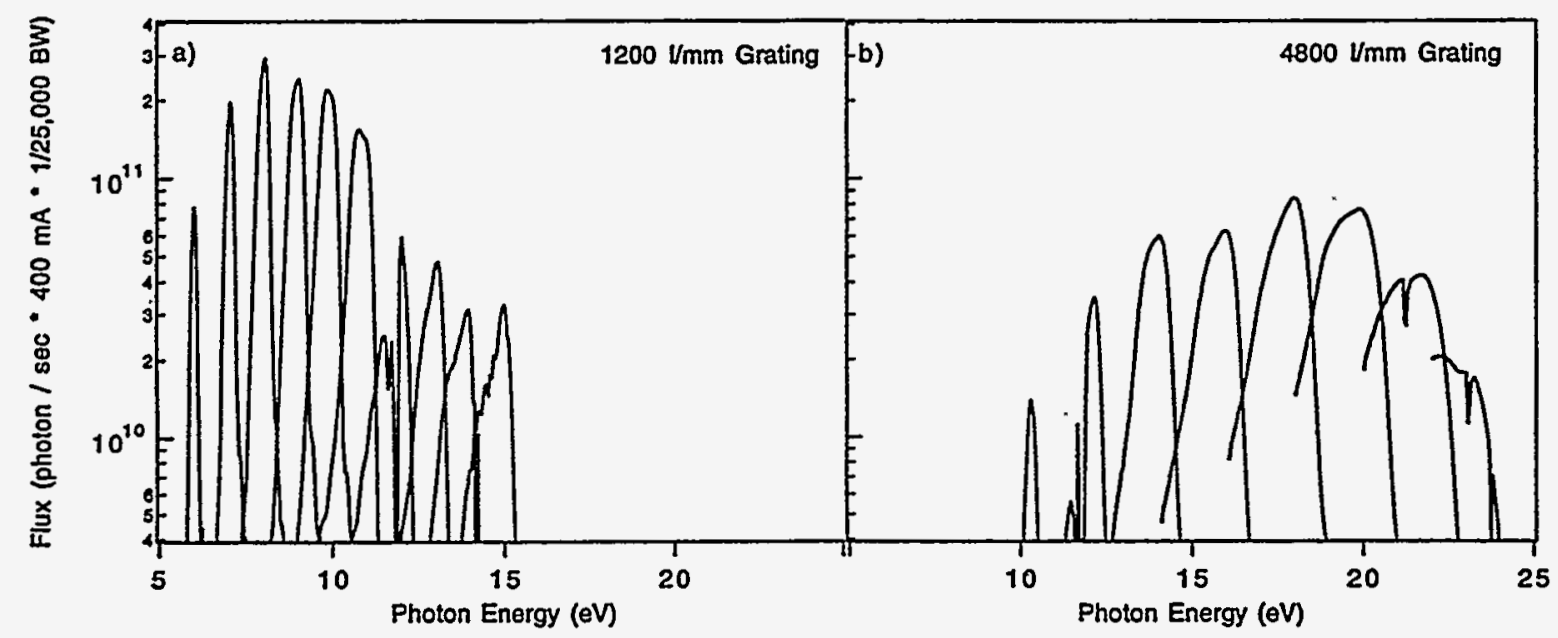

Figure 6. The flux through the branch line to end station 2 including the Eagle monochromator employing either the 1200 $\mathrm{V} / \mathrm{mm}$ or $4800 \mathrm{~J} / \mathrm{mm}$ grating. The intensity was detected by a NIST calibrated Si n on p photodiode.

The measured intensity is in the range of $10^{10}$ to $10^{11}$ photon / sec, about an order of magnitude lower than the calculations. ${ }^{1}$ The shape of the flux curve with the $1200 \mathrm{~J} / \mathrm{mm}$ grating can be readily understood. The maximum at $8 \mathrm{eV}$ corresponds to the on-blaze condition, and the decreasing intensity beyond $11 \mathrm{eV}$ follows the reflectivity of the $\mathrm{Al} / \mathrm{MgF} 2$ coating. In contrast to what is observed with the $4800 \mathrm{l} / \mathrm{mm}$ grating, that intensity curve is expected to be broad with the maximum close to the nominal on-blaze energy of $12 \mathrm{eV} .13$

The throughput of the branch line to end station 2 was investigated by measuring the reflectivities of the M4, M5 and M6 mirrors. A deuterium lamp and an interference filter (Acton Research Corp.), having maximum transmission at $10.3 \mathrm{eV}$, was added to an existing reflectometer. ${ }^{14}$ The radiation from the deuterium lamp is unpolarized in comparison with the beamline, where the reflections are with p polarization. Incidence angles were chosen to duplicate the geometry in the beamline. 
The measured reflectivity of the M4 mirror was 0.50 at $78^{\circ}$, and for the M6 mirror the result was 0.78 at $81^{\circ}$. The Mi4 mirror has a silicon coating, while the M6 mirror is an uncoated silicon substrate. The reflectivity of the M4 mirror agrees with the results of Windt et al. for an electron beam evaporated Si film. ${ }^{3}$ Using Auger depth profiling, Windt et al. observed oxygen and, to a lesser extent carbon, throughout their Si coating. The as-polished silicon M6 mirror is expected to have an oxide layer, about $10 \AA$ thick at the surface. The measured reflectivity of the M5 mirror was 0.45 at $10^{\circ}$, also in agreement with Windt et al. ${ }^{3}$ At $10.3 \mathrm{eV}$ photon energy the uncoated silicon substrate had higher reflectivity than the silicon coated mirror, and the high performance of $\mathrm{SiC}$ is confirmed as a normal incidence reflector.

Contamination blemishes matching the beam footprint were observed on the M4 and M5 mirrors, but not on the M6 mirror. On the contaminated regions of the mirror surfaces, lower reflectivities were observed. In the case of the M5 mirror, the decrease in reflectivity was determined to be a factor of six. Previous to the measurements shown in figure 6, the M4 and M5 mirrors were cleaned using the UV / ozone method. ${ }^{15}$ In addition, the pumping speed was increased at the M4 and M5 mirror chambers.

A final uncertainty in the beamline transmission is the diffraction efficiency of the gratings, which depends on the shape of the groove profile. The scalar efficiency employed in the flux calculations ${ }^{1}$ is expected to give higher values than the efficiencies of the actual fabricated gratings. Unfortunately, the large 1200 and $4800 \mathrm{l} / \mathrm{mm}$ gratings are not compatible with the reflectometer used for the mirror reflectivity measurements.

\section{RESOLUTION}

The resolution of the Eagle monochromator was determined by performing photoionization efficiency measurements in end station 2. In this experiment an atomic or molecular beam crosses the VUV radiation with photoions detected by a quadrupole mass spectrometer. After passing through the interaction region, the radiation strikes a silicon photodiode used to normalize the ion signal. Subsequent to these measurements the silicon photodiode was replaced with a tungsten photocathode, which is insensitive to beam damage.

The photoionization efficiency spectrum of neon between the ${ }^{2} \mathrm{P}_{3 / 2}$ and ${ }^{2} \mathrm{P}_{1 / 2}$ thresholds is shown in figure 7 . For this spectrum the $4800 \mathrm{~V} / \mathrm{mm}$ grating was used with $10 \mu \mathrm{m}$ entrance and exit slit widths. The grating translation remained fixed. The photon energy step size was $0.1 \mathrm{meV}$ and the collection time at each step was $3 \mathrm{sec}$. A small electric field of $0.76 \mathrm{~V} / \mathrm{cm}$ was employed to extract the ions from the interaction region, while minimizing the influence of the Stark effect on the spectrum.

Above the ionization potential $\mathrm{Ne}^{+}{ }^{2} \mathrm{P}_{3 / 2}$, two Rydberg series $2 \mathrm{p}^{5} \mathrm{~ns}$ and $2 \mathrm{p}^{5} \mathrm{nd}$ ' converge to the spin-orbit excited $\mathrm{Ne}^{+}$ ${ }^{2} \mathrm{P}_{1 / 2}$ ionization limit. ${ }^{16}$ The spectroscopic content of figure 7 has been presented separately in Hsu et al. ${ }^{17}$ The neon $2 \mathrm{p}^{5} \mathrm{~ns}$ and $2 p^{5}$ nd series autoionize with both series having very narrow natural linewidths. A very high resolution two step laser excitation experiment determined $\Gamma_{14 s^{\prime}}=25 \mu \mathrm{V}$ and $\Gamma_{12 \mathrm{~d}^{\prime}}=8 \mu \mathrm{V}$. ${ }^{18}$ In contrast for argon, krypton and xenon, the linewidth of the nd' series is much larger than the $n s^{\prime}$ series. ${ }^{7}$ As a result from the neon spectrum, the resolution of the Eagle monochromator can be observed directly from the lineshapes of the Rydberg resonances.

The observed linewidth of the neon $2 p^{5} 17 s^{\prime}$ resonance, shown in the inset of figure 5, is $0.3 \mathrm{meV}$ (fwhm) corresponding to a $\lambda$ resolution of $0.008 \AA$ or a resolving power of 70,000 . The resolution of the monochromator using the other, $1200 \mathrm{ymm}$ grating was evaluated with the photoionization efficiency spectrum of NO obtained at $10 \mu \mathrm{m}$ entrance and exit slit widths. At $9.3 \mathrm{eV}$ photon energy, resonance linewidths of $0.22 \mathrm{meV}$ (fwhm) were observed equivalent to a $\lambda$ resolution of $0.03 \AA$ or a resolving power of 40,000 . The resolution, $\Delta \lambda$, of the two gratings differs by about a factor of four inversely following the ratio of the grating periods.

The experimental resolution is determined by a number of factors: the slit width and diffraction limits, aberrations, grating fabrication errors, the alignment of the monochromator and the precision of the grating drive. The ray tracing described in Ref. 1 showed that the calculated resolving power of the Eagle monochromator with $4800 \mathrm{~V} / \mathrm{mm}$ grating was 200,000. Also, the resolving power was predicted to be nearly constant independent of the photon energy, which was a consequence of the source size increasing with $\lambda$ because of diffraction. 


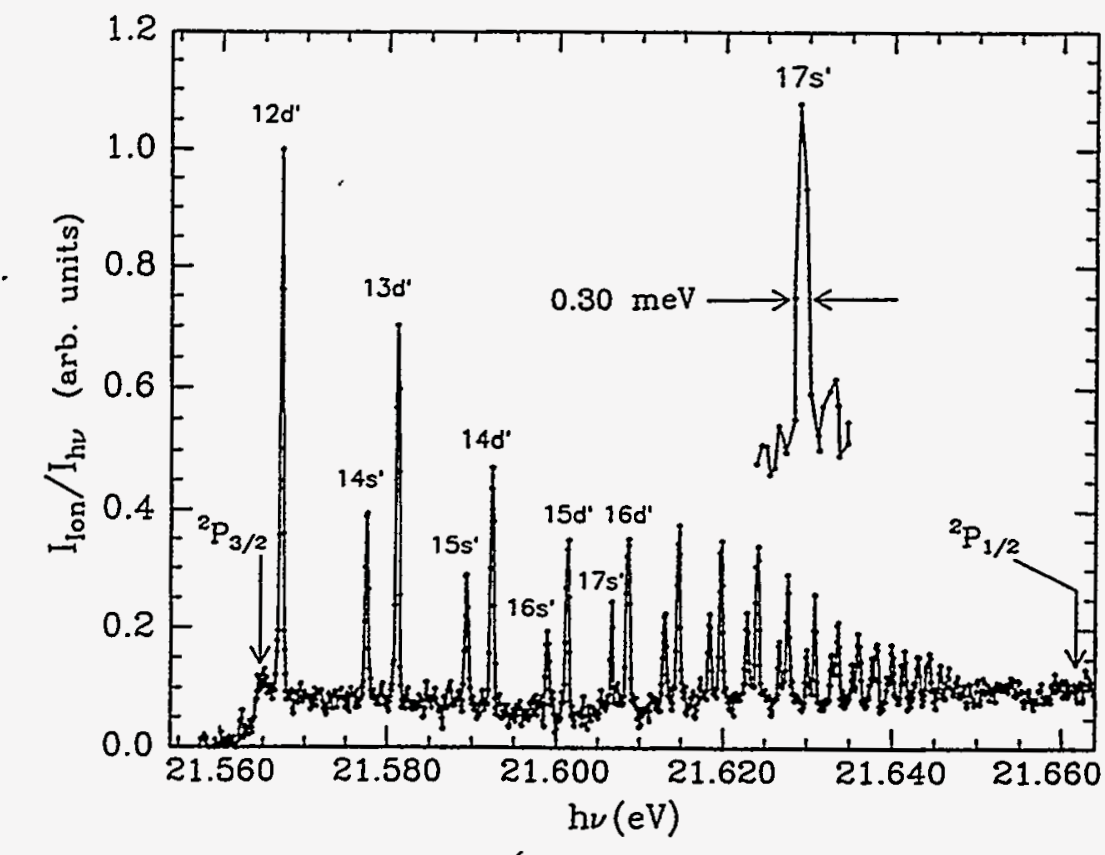

Figure 7. The photoionization efficiency of neon measured with the $4800 \mathrm{l} / \mathrm{mm}$ grating using $10 \mu \mathrm{m}$ entrance and exit slit widths.

The next resolution factor involves the slope errors of the grating blank and the accuracy of the ruling of the grating grooves. The figure of the $4800 \mathrm{l} / \mathrm{mm}$ grating was measured with the AlS long trace profiler with a result of $3.2 \mu \mathrm{rad}$ rms over a $30 \mathrm{~mm}$ length. Two $6.65 \mathrm{~m}$ spectrographs, at NIST and at the University of Maryland, have employed replicas from the same Hyperfine $4800 \mathrm{l} / \mathrm{mm}$ master grating. From the NIST spectrograph a $\lambda$ resolution of $0.009 \AA$ at $800 \AA$ has been reported; 19 Orth et al. ${ }^{13}$ obtained a resolution of $0.006 \AA$ at $1100 \AA$ with the UM spectrograph. The resolution contribution, $\Delta \lambda$, of the grating slope errors varies slowly with photon energy, $\Delta \lambda-2 \mathrm{~d} \cos \alpha \Delta \alpha$.

The alignment of the entrance slit, grating and exit slit is also critical. The grating roll and yaw were adjusted to maximize the intensity at zero order and at one photon energy, $12.7 \mathrm{eV}$. The ideal rotation of the entrance and exit slits should be at small, opposing angles from the direction parallel to the grating grooves. 1,5 In practice for the neon spectrum, no significant change was observed with small rotations of the slits, and the slits were left horizontal. The translation of the grating was varied to optimize the focus.

For monochromators the grating rotation drive is a last important factor for the resolution. Noise was observed in the laser interferometer encoding the grating angle. Two sources of mechanical vibration were identified, a water chiller and a cryopump compressor, and attempts were made to vibrationally isolate both. At present, vibrations in the grating angle limit the minimum step size to about $0.0025 \AA$, i.e. $0.1 \mathrm{meV}$ at $21.6 \mathrm{eV}$. The resolution contribution, $\Delta \lambda$, of the grating angular stability varies slowly with photon energy. The measured resolving power of 70,000 is caused mainly by the accuracy of the grating optical surface and the stability of the grating rotation drive. Since the resolution contribution, $\Delta \lambda$, from both these factors vary slowly with $\lambda, \Delta \lambda$ is expected to remain nearly constant.

The performance of the ALS Chemical Dynamics Beamline has been characterized and is in operation for user experiments. The harmonic suppression of the gas filter was determined by using a transmission grating spectrometer. An attenuation of higher harmonics by greater than four orders of magnitude was observed. The flux of the white beam branchline, measured with a calorimeter, was $10^{16}$ photon $/ \mathrm{sec}$ in agreement with the predicted intensity. The flux of the monochromatic branchline, determined with a NIST-calibrated photodiode, was at the maximum $3 \times 10^{11}$ photon / ( $\sec 1 / 25,000$ band width). The resolution of the off-plane Eagle monochromator was demonstrated with the photoionization spectrum of neon. A resolving power of 70,000 was observed, which is among the highest achieved by a VUV monochromator. 


\section{ACKNOWLEDGMENTS}

The authors wish to thank H. Padmore and E. Gullikson for helpful discussions. The contributions of R. DiGennaro; C. Corradi, B. Gee, N. Andreson, G. Morrison, and A. Robb in constructing this beamline must be acknowledged. B. Dolan, J. Billington and D. Schoeffel of McPherson must also be thanked for their efforts in building the Eagle monochromator. This work is supported by the Director, Office of Energy Research, Office of Basic Energy Sciences, Chemical Sciences Division and Materials Sciences Division of the U.S. Department of Energy under Contract Number DE-AC03-76SF00098.

\section{REFERENCES}

1. M. Koike, P.A. Heimann, A.H. Kung, T. Namioka, R. DiGennaro, B. Gee and N. Yu, "VUV high resolution and high flux beamline for chemical dynamics studies at the Advanced Light Source," Nucl. Instrum. Methods A 347, 282-286 (1994).

2. A.G. Suits, P. Heimann, X. Yang, M. Evans, C.W. Hsu, K.T. Lu, Y.T. Lee and A.H. Kung, "A differentially pumped harmonic filter on the Chemical Dynamics Beamline at the Advanced Light Source," Rev. Sci. Instruments 66, 4841-4844 (1995).

3. D.L. Windt, W.C. Cash, M. Scott, P. Arendt, B. Newman, R.F. Fisher, A.B. Swartzlander, P.Z. Takacs and J.M. Pinneo, "Optical constants for thin films of C, diamond, $\mathrm{Al}, \mathrm{Si}$, and CVD SiC form $24 \AA-1216 \AA$," Applied Optics 27, 279-295 (1988).

4. M. Koike, P.A. Heimann and T. Namioka, "Design of a high-resolution step-and-scan type monochromator capable of tuning to undulator radiation over a wavelength range of $80-180 \mathrm{~nm}$," Proc. SPIE 2856, this proceedings.

5. T. Namioka, "Design of High-Resolution Monochromator for the Vacuum Ultraviolet. An Application of Off-Plane Eagle Mounting," J. Opt. Soc. Am. 49, 961-965 (1959).

6. K. Ito, T. Namioka, Y. Morioka, T. Sasaki, H. Noda, K. Goto, T. Katayama and M. Koike, High-resolution VUV spectroscopic facility at the Photon Factory," Applied Optics 25, 837-847 (1986).

7. K. Maeda, K. Ueda and K. Ito, "High-resolution measurement for photoabsorption cross sections in the autoionization regions of $\mathrm{Ar}, \mathrm{Kr}$ and Xe," J. Phys. B 26, 1541-1545 (1993).

8. D.A. Mossessian, P. A. Heimann, E. Gullikson, R.K. Kaza, J. Chin and J. Akre, "Transmission grating spectrometer for characterization of undulator radiation," Nucl. Instrum. Methods A 347, 244-248 (1994).

9. L.R. Canfield, J. Kerner and R. Korde, "Stability and quantum efficiency performance of silicon photodiode detectors in the far ultraviolet," Applied Optics 28, 3940-3943 (1989).

10. D.Y. Smith, E. Shiles and M. Inokuti, in Handbook of Optical Constants of Solids, E.D. Palik, ed., 369-406, Academic Press, New York, 1985.

11. C.E. Moore, Circular of the National Bureau of Standards 467, 211-215,1949.

12. R. Korde, J.S. Cable and L.R. Canfield, "One gigarad passivating nitrided oxides for $100 \%$ internal quantum efficiency silicon photodiodes," IEEE Transactions on Nuclear Science 40, 1655-1659 (1993).

13. F.B. Orth, M.L. Ginter, K. Yoshino and C.M. Brown, "Vacuum UV performance of a new 6.65 -m concave diffraction grating with 4800 grooves/mm," Applied Optics 25, 2218-2220 (1986).

14. E.M. Gullikson, J.H. Underwood, P.C. Batson and V. Nikitin, "A soft X-ray / EUV reflectometer based on a laser produced plasma source," X-ray Sci. Technol. 3, 283-299 (1992).

15. R.W.C. Hansen, J. Wolske, D. Wallace and M. Bissen, "Cleaning of optical surfaces with photogenerated reactants," Nucl. Instrum. Methods A 347, 249 (1994).

16. K. Radier and J. Berkowitz, "Photoionization mass spectrometry of neon using synchrotron radiation: anomalous variation of resonance widths in the noble gases," J. Chem. Phys. 70, 216-220 (1979).

17. C.-W. Hsu, M. Evans, P. Heimann, K.T. Lu and C.Y. Ng, "A High Resolution Photoionization Study of Ne and Ar: Observation of Mass Analyzed Threshold Ions Using Synchrotron Radiation and dc Electric Fields," J. Chem. Phys., to be published.

18. J. Ganz, A. Siegel, W. Bussert, K. Harth, M.W. Ruf, H. Hotop, J. Geiger and M. Fink, "On the Ne(2p $\left.p^{5} n s^{\prime}, n d '\right)$ autoionization resonances: high-resolution measurement and quantum defect analysis," J. Phys. B 16, L569-L576 (1983).

19. H.D. Morgan, J.D.E. Fortna, H.M. Seyoum, M.L. Furst, L.R. Hughey, D.C. Humm and A. Asfaw, "The Very High Resolution Spectrometer at the National Institute of Standards and Technology," Nucl. Instrum. Methods A 347, 287-290 (1994). 